\title{
Democracia e Dominação: Uma Discussão (via Índia) com Referência à América Latina (Brasil)*
}

José Maurício Domingues

\section{DEMOCRACIA E SERIALIDADE}

F $m$ seu longo livro sobre a democracia, Habermas definiu, de ma¿ neira algo surpreendente, o Estado democrático constitucional (Rechstaat) como que baseado no "exercício burocrático da dominação legal (Herrschaft)":

Em suma, o Estado torna-se necessário como um poder (Gewalt) sancionador, organizador e executivo, uma vez que a lei tem de ser efetivada [...]. Estes são certamente complementos não apenas funcionalmente necessários para o sistema do direito, mas antes implicações legais objetivas, que estavam contidas in nuce nos direitos subjetivos [...]. Não é a forma legal como tal que legitima a dominação política, mas somente seu vínculo com o direito legitimamente produzido (Habermas, 1992:168-170; grifo do original; tradução do autor).

Essa definição é, com efeito, mais surpreendente porque surge no bojo do que seria um esforço sistemático para substituir as teorias elitistas da democracia por um modelo "discursivo", comunicativo e muito mais democrático. É verdade que o abandono da ideia de "colonização" do mundo da vida por sistemas autorregulados, processo no qual o direito poderia operar como "meio" da colonização destes antes que

\footnotetext{
* Agradeço a João Feres seus comentários à versão anterior deste artigo.

DADOS - Revista de Ciências Sociais, Rio de Janeiro, Vol. 52, nº 3, 2009, pp. 551 a 579.
} 
como expressão daquele (idem, 1981, vol. 2:458 e 536-539), anuncia a teoria benigna e um tanto aguada da democracia que emergiria de seu modelo mais geral ulteriormente. Neste, ao passo que o Estado segue sendo um sistema autorregulado conduzido pelo poder (ladeado pela economia, dirigida pelo dinheiro), o mundo da vida, mediado por meio da ação comunicativa e da interação significativa, seria representado pela sociedade civil, um foco de solidariedade. Esta, por sua vez, seria discursivamente mediada por meio das esferas públicas, que permitem uma "política deliberativa" que gera normas (legalmente) vinculantes, calcadas na "liberdade subjetiva" (produzidas histórica e intersubjetivamente). O universalismo teria de resultar desse processo público-discursivo. $\mathrm{O}$ "poder comunicativo", por um lado, e o "poder político" mais o "poder administrativo" (conceitos sempre difíceis de diferenciar em sua obra), por outro, são totalmente distinguidos no "Estado democrático constitucional", que já não é visto como o centro da sociedade. Eis aí o que é democracia para Habermas, para além da teoria elitista dos grupos de poder, bem como para além das preocupações dos pluralistas com interesses (fixos) livremente expressos (1992, especialmente pp. 359 ss). Sua definição contrasta, assim, com os tipos de dominação em Weber (1980 [1921-1922]), em particular a racional-legal, mas remete diretamente a eles.

Cohen e Arato (1992) expandiram historicamente essa divisão e sublinharam o caráter triplo da vida social (mercado, estado, sociedade civil), o papel das associações e dos movimentos sociais, assim como o cunho autolimitante destes últimos (que não deveriam visar assumir a "sociedade política"). A participação e inclusive a desobediência civil são cruciais em suas propostas, porém o papel constitucional do direito e os limites que impõe a todos os membros da sociedade, um ensinamento liberal, são centrais em sua concepção.

Mais recentemente, Alexander (2006) produziu outra versão mais próxima da "esfera civil", na verdade retomando o conceito de Parsons de "comunidade societária" e uma oposição binária entre o "sagrado" e o "profano", aquela relativa àquilo que estimamos na sociedade civil. Se Alexander aceita os limites impostos por formas "incivis" de vida social e como a esfera civil se encontra entrelaçada com eles, insiste em sua especificidade em termos de solidariedade, universalismo e individualismo, como o elemento-chave da democracia, para além da hierarquia e da desigualdade, assim como do particularismo, inevitável em outras esferas sociais principais. 
Em Habermas (1990:150-159; 1992:632-659), esse procedimento de construção da democracia está intimamente ligado ao que chamou de "patriotismo constitucional", cujas origens se encontram na recusa ao nacionalismo étnico alemão que culminou no nazismo. Ou seja, Habermas opõe fortemente o universalismo em termos normativos ao particularismo, conquanto processos históricos concretos sejam requeridos para que esse patriotismo cívico se estabeleça. Essa é, em certa medida, também a perspectiva de Anderson (1998, sobretudo caps. 1 e 17), que enfatiza o que chama de "serialidade aberta" (infinita e mais livre) e a força integrativa, universalizante, do nacionalismo (em que aquela pode fluir dentro de certos limites), contra o particularismo que se difunde em tempos recentes, com sua "serialidade fechada", repetitiva, rígida, finita, e sua política da identidade, seja no sudeste da Ásia, seja em outros lugares do planeta, com frequência sob as vestes da política étnica (a estatística sendo originalmente um de seus pilares-mores).

De forma quase inversa, Chatterjee (2004) introduziu, para falar da política popular na "maior parte do mundo", a oposição entre a política da "sociedade civil", em sentido mais tradicional, como legal e formalmente estabelecida, e a política da "sociedade política". Esta última é uma esfera em que os governos - ou as práticas de governamentalidade - implementam políticas que têm de lidar com práticas ilegais e informais levadas a cabo por populações que se convertem em alvo de perspectivas particulares (isto é, "fechadas" versus universais, "abertas"), a serviço, hoje globalmente, do capital, enquanto que, ao mesmo tempo, lutam para afirmar seus próprios desejos e necessidades:

Em suma, a ideia clássica de soberania popular, expressa nos fatos político-legais da cidadania igualitária, produziu o constructo homogêneo da nação, ao passo que as atividades de governamentalidade requerem classificações múltiplas, que se cruzam e transformam, de populações como alvos de políticas múltiplas, produzindo um constructo necessariamente heterogêneo do social (ibidem:36; tradução do autor).

Esse foi, aliás, um problema que, de acordo com Chatterjee (ibidem:36-38), Marshall não entendeu em sua afirmação clássica sobre os direitos civis, políticos e sociais, os quais são eles mesmos heterogêneos e levam diretamente à governamentalidade. Já esta é conceito que, por sua vez, nos permitiria ir além dos conceitos clássicos de "dominantes" (rulers) e "dominados" (ruled). A democracia na Índia tem se desenvolvido, de maneira bastante ambígua, segundo ele, a partir 
da complicada dinâmica dessa "sociedade política" e de seu caráter heterogêneo, além de sua relação particularística com o Estado. Chatterjee aparentemente assume como dados, ao menos tanto na Índia quanto no Ocidente, os aspectos constitucionais da democracia, embora esta "democracia capitalista moderna", assevera de modo curioso, pertença somente ao último. O autor não focaliza explicitamente o movimento e os partidos Hindutva (o nacionalismo hindu radical e excludente), mas esse desenvolvimento lamentável da política indiana é um dos alvos subjacentes em sua crítica à modernidade homogeneizante (1998:228-231, com tons frankfurtianos), que permanece na retaguarda de seu argumento à medida que ele atribui aquela tendência homogeneizante apenas à dinâmica do capitalismo. Por outro lado, pode-se legitimamente perguntar se o Hindutva não deveria ser visto exatamente como política étnica radical e seu nacionalismo do tipo de uma serialidade fechada etnicamente determinada ${ }^{1}$.

Embora a questão dessa "sociedade política" seja muito mais dramática do que qualquer fato que se possa encontrar no Ocidente, decerto espelha discussões encetadas por formas de governamentalidade neoliberais e maneiras de operar por meio das próprias noções de liberdade e responsabilidade individual (Rose, 1999). Conquanto a influência de Gramsci sobre Chatterjee (2008) permaneça difusa, aqui ele se apoia em Foucault e explicitamente argumenta contra a preferência de Anderson pelo universalismo, em conexão com o nacionalismo homogeneizante, e em favor do particularismo, bem como, até certo ponto, da informalidade, reconhecendo ainda o caráter heterogêneo do espaço social (em contraposição ao espaço homogêneo do capital). Três formas do moderno exercício do poder, na verdade, da "dominação" - soberania, disciplina e biopolítica -, foram delineadas nos trabalhos do último Foucault (1997 [1976], especialmente pp. 23, 24, 30-36 e 215-225; 1979). A soberania descende da problemática da legitimidade do poder real no Ocidente e foi, no século XVIII, traduzida nos direitos do cidadão, a rigor, na concepção de Foucault, sempre transferida ao Estado e terminando por meramente mascarar o funcionamento do poder disciplinar. Este foi aplicado ao indivíduo, em torno a saberes específicos, no conjunto da sociedade, sem se concentrar no Estado. Já a biopolítica, que Foucault às vezes denomina governamentalidade, lida com as populações e a "regulação" da vida, permitindo um tipo de sobrevida para o Estado diante do poder disciplinar. Enquanto a segunda forma leva a uma sociedade "normalizada", a terceira se vincula ao Estado por meio da mesma noção de "norma". Essas formas são produti- 
vas, e não apenas "repressivas". Foucault, ademais, não considerou suficiente, nem de fato adequado, pensar o poder basicamente em termos da soberania do Estado, opondo a esta os direitos dos cidadãos. Em vez disso, um discurso antidisciplinar mais amplo era necessário.

É contra esse pano de fundo que quero discutir a democracia na América Latina, em particular no Brasil, nas últimas décadas (o subcontinente havendo sido mencionado, aliás, somente por Cohen e Arato (1992), entre esses autores). Em primeiro lugar, proponho-me aqui a rejeitar a ideia de Habermas, para mim absurda, de que a democracia equivale à dominação, não importando como esta é definida. A democracia existe, e pode apenas sobreviver, contra a dominação, mesmo que não possamos hoje divisar formas de democracia que possam dar cabo dela afinal, falamos do Estado, controlado por coletividades políticas e burocráticas, separadas dos cidadãos e baseadas em um aparato hierárquico e no "comando" (Befehl), estando esse Estado, além disso, nas sociedades modernas, estreitamente entrelaçado com o capitalismo e suas classes dominantes (ainda que a dominação não possa ser reduzida seja ao Estado, seja às classes sociais, não obstante a importância que ele ou elas possam ter). Fazer da necessidade virtude já é uma tarefa difícil, mas transformar o vício em virtude não faz sentido. É verdade que esses sistemas políticos são competitivos, com as coletividades dominantes sendo substituídas de tempos em tempos por processos eleitorais, conquanto os aparatos burocráticos estatais escapem desses processos. De qualquer modo, grandes máquinas organizacionais e hierárquicas, com múltiplas camadas, mantêm-se ativas em múltiplos níveis. Logo, se não temos como romper com as formas elitistas da democracia, sejamos ao mesmo tempo mais radicais e mais realistas, deixando patentes as limitações do presente, mas simultaneamente as desafiando do ponto de vista da relação entre o Estado e a sociedade. É por isso que a ideia de liberdade como uma "criação" (ou seja lá como for que se a denomine) do poder me parece também totalmente insatisfatória: a liberdade não é um produto da dominação, mas seu exato oposto, embora certamente se relacione à noção de poder também, afirmativamente por parte das subjetividades individuais e coletivas.

Em segundo lugar, muitos na América Latina têm assinalado os problemas que a democracia tem de encarar na região. Não viso contestar esses problemas, mas espero oferecer uma visão mais larga e otimista da questão. Afinal, a "sociedade civil", no sentido de Habermas, bem como no de Chatterjee, está se expandindo - isto é, associações e movi- 
mentos sociais têm de modo geral se fortalecido - em ritmos distintos e em países diferentes, em momentos distintos, com a inclusão formal e legalmente vinculada avançando de maneira acelerada nas últimas décadas em certo número de aspectos, em especial em termos estritamente políticos. A "sociedade política", no sentido que Chatterjee lhe atribui, tem fortemente se reiterado em muitas áreas também, com a simples violência igualmente se expandindo. De todo modo, ao passo que essas categorias de fato possuem uma materialidade própria, são problemáticas se apresentadas dessa forma tão aguda. A dicotomia que opõe aquelas "sociedades" não pode ser aceita, a menos que se adote algo como a concepção binária de Alexander (2006) da divisão "sagrado-profano", com um sinal invertido no que concerne a Chatterjee e com, além disso, uma suposição de que a divisão provê mais do que uma estrutura discursiva, o que não é de maneira nenhuma o caso. $\mathrm{O}$ longo debate acerca do dualismo na América Latina deveria nos aconselhar contra tal uso dos conceitos, porquanto esses dois mundos se encontrem muito mais entrelaçados do que Chatterjee sugere.

Visando alcançar minhas metas neste artigo, tomarei como apoio ideia que desenvolvi em termos mais gerais, assim como em relação à América Latina. Para começar, afasto qualquer visão dualista. De ângulo mais positivo, introduzirei em especial o par cidadania instituinte e instituída, mais o conceito de "abstrações reais" e o retrato em quatro dimensões do imaginário moderno como baseado em liberdade, igualdade, solidariedade e responsabilidade, que aparecem em conexão e em oposição à dominação, desigualdade, fragmentação, egoísmo e irresponsabilidade (Domingues, 2002; 2009a) ${ }^{2}$.

É verdade que, em muitos aspectos e especialmente em alguns países, a democracia parece frágil. Nesse sentido, uma tensão, de modo algum negativa e que exploraremos adiante, por vezes tem papel importante a cumprir, ou seja, aquela entre o que Eisenstadt (1999, sobretudo cap. 2) denomina aspectos "participativos" e "constitucionais" da democracia (embora simples tentativas de eliminar ou restringir a democracia mediante perspectivas antidemocráticas ou elitistas serem repetidamente muito mais problemáticas). É por meio dessa tensão que a articulação do que seriam para Castoriadis (1975:138 ss e 493 ss; 1999:119) os dois principais aspectos da democracia - o poder do "demos", enraizado na autonomia dos agentes, e sua autolimitação, por meio de um "nomos" - poderia ser alcançada. Talvez uma solução mais interessante possa ser assim obtida para os dilemas apresentados 
pelas concepções opostas de Habermas e seus associados, por um lado, e a de Foucault e Chatterjee, por outro.

Comecemos por uma breve discussão dos desenvolvimentos contemporâneos da democracia na América Latina. Debruçar-nos-emos então sobre certos aspectos da democracia brasileira. Parece-me que, tudo considerado, e a despeito dos muitos problemas que podem ser localizados, a democracia tem florescido na região, bem como no Brasil, logo, de maneira alguma ficando estagnada ou se erodindo, como alguns sugeririam (Mainwaring e Pérez-Liñan, 2005). Finalmente, retornaremos a uma discussão teórica mais sistemática.

\section{Tendências Democratizantes na América Latina: Avanços, Limites e Problemas}

A crítica de O'Donnell (1994; 1996) às democracias liberais que existem na América Latina tornou-se bem conhecida. Ele enfatizou seu aspecto "delegativo", ou seja, a eleição de líderes poderosos (como Carlos Menem, na Argentina, e Alberto Fujimori, no Peru), dando-lhes um cheque em branco que lhes permitiu fazer o que quisessem, até mesmo mudar suas políticas iniciais e perspectiva geral, fazendo-as irreconhecíveis. O'Donnell sublinhou também os traços particularistas de muitos desses sistemas políticos nos quais o clientelismo se destacava. Enfim, a falta de controle e de transparência (accountability) desses detentores do poder em relação à sociedade foi também enfatizada. Outros, se reconheceram avanços em toda a América Latina, têm sido muito críticos a países onde os governos são forçados a renunciar em função de protestos populares sem supostamente respeito por regras constitucionais (Mainwaring e Hagopian, 2005:1-2) (algo que de resto ocorre quando esses governos não cumprem suas promessas e rompem com as políticas com que se haviam comprometido). Roniger (2005) sublinhou ainda o que via como "neopopulismo" e "neoclientelismo", e sua ação deletéria sobre o tecido democrático, a persistência da violência e a falta de respeito pelos direitos civis básicos, levando talvez a uma erosão da confiança na democracia, tal qual medida por instrumentos como o "Latinobarómetro" - problema destacado também por outros estudos acerca do tema (Méndez, O’Donnell e Pinheiro, 2003).

"Populismo" parece-me uma construção problemática, que dificilmente fazia sentido na perspectiva proposta por Gino Germani, profundamente devedora do funcionalismo e da teoria da modernização 
(ver Domingues e Maneiro, 2007), sendo hoje demasiado vaga conceitualmente, operando mais como um termo de abuso e denúncia de demagogia em geral ("cesarismo", seja "progressista", seja "conservador", seria provavelmente um conceito melhor nesse caso). $\mathrm{O}$ "clientelismo", contudo, tem sido traço realmente recorrente e saliente da política de toda a região, como vários estudos recentes demonstram (por exemplo, para a Argentina e o México, ver Auyero, 2001; Fox, 1997). O mesmo é verdadeiro no que se refere à efetivação da cidadania civil por um Estado ainda "despótico" que amiúde trata suas populações como "súditos" e possui um "poder infraestrutural" relativamente reduzido, isto é, não é capaz de governar muito da sociedade por intermédio de suas próprias instituições (Mann, 2006), abandonando seus "cidadãos" à sua sorte em face de condutas criminosas (especialmente quando são pobres) e tratando violentamente e, com frequência, de maneira ilegal aqueles que seriam transgressores da lei, em outras palavras, punindo-os sem respeito por seus direitos civis (mais uma vez, especialmente quando são pobres). Os direitos sociais tiveram pior destino, uma vez que foram efetivados de modo bastante limitado durante o período do Estado desenvolvimentista e do corporativismo e, quando ocorreu a democratização, a partir da década de 1980, o credo neoliberal não tinha lugar para eles, ao contrário (Barrientos, 2004).

Em seu argumento, Roniger (2005) assinala, contudo, conquanto por vezes soe algo pessimista, que essa confiança reduzida na democracia pode significar simplesmente que ela está consolidada, mas que os cidadãos não estão lá muito satisfeitos com seus resultados. Afinal, podemos acrescentar, os cidadãos parecem estar insatisfeitos não somente na América Latina, mas em todo o mundo, especialmente em função das reformas neoliberais (cf. Hagopian, 2005:321-324). Roniger também assinala certo número de mudanças que têm levado, a despeito desses problemas e da falta de recursos de muitos grupos populares para participar plenamente da política, a novas formas de política participativa e a uma perspectiva da democracia que vai além das teorias "elitistas" que prevaleceram na vida acadêmica durante a transição das ditaduras militares e após seu fim nos anos 1980-1990. Ao passo que estas eram "minimalistas", as novas experiências implicaram participação de massa, controle público e deliberação. É isso que estudos, por exemplo, sobre o México (controle eleitoral) e o Brasil (orçamento participativo) mostram, assim como sugerem discussões sobre uma esfera pública ampliada e pluralizada (Avritzer, 2002; Avritzer e Costa, 2005), já para não falar do que a paulatina abertura, e por vezes plurali- 
zação, dos sistemas judiciais evidencia (Domingues, 2009a, cap. 1). Mais recentemente, em particular a Bolívia tem sido o cenário para um aprofundamento das práticas democráticas, da forte mobilização social e de eleições tradicionais à grande participação comunitária e ao uso constante de referendos (um instrumento comumente usado na Europa, porém odiado pelos conservadores na América Latina), a despeito de tensões relativas a "serialidades étnicas" (García Linera, 2004; Domingues et alii, 2009).

Meu recente argumento é também que, a despeito da persistência do clientelismo, da importância dos poderes "fáticos" (tais como a alta concentração dos meios privados de comunicação de massa, programaticamente orientados para o neoliberalismo) e as restrições ao exercício de direitos, a democracia nunca foi tão forte na América Latina. O subcontinente vem passando, nas últimas décadas, por uma verdadeira "revolução molecular", a despeito do também corrente projeto "transformista" do neoliberalismo, que propugna por uma democracia mínima - configurando-se assim dois "giros modernizadores" em competição, os quais, em seu choque, têm moldado a região nas últimas décadas (Domingues, 2009a, cap. 3). O télos do imaginário moderno, tendo em seu centro a liberdade igualitária, tem se traduzido em ampla mobilização social, levando a uma mudança dos grupos políticos dominantes (as chamadas "elites", termo que deveria ser realmente evitado, ao menos em função de sua bagagem ideológica excessivamente pesada, que inclui o papel negativo ou limitado que reserva para as "massas") e ao restabelecimento, mudança e consolidação das instituições democráticas. Na verdade, a defenestração de políticos que traem seus compromissos básicos deveria ser vista como um avanço na região, que produtivamente evidencia a tensão antes mencionada entre os aspectos constitucionais e participatórios da democracia, incluindo a desobediência civil, em particular na medida em que isso não significa que tenham sido substituídos por líderes militares. Em vez disso, os vice-presidentes assumiram o cargo ou novas eleições foram convocadas, sem quebra das regras constitucionais. Ademais, presidentes "delegados", como Menem e Fujimori, têm sido presos, processados e podem terminar seus dias na cadeia por corrupção e abuso contra os direitos humanos.

Ondas de mobilização popular vão e vêm na América Latina; estão possivelmente na vazante na maior parte desses países, se bem que não em todos eles, mas seu legado é inegável. A constitucionalização tem 
também progredido, implicando cobertura legal mais forte para o Estado e mais legitimação, bem como um reconhecimento mais avançado dos direitos e a flexibilização de códigos jurídicos anteriormente mais rígidos, com uma tendência a avanços nos sistemas legais e no império da lei, não obstante problemas e limitações. A moldura estatal tem se mostrado, de modo geral, mais adaptável e capaz de responder à crescente complexidade da modernidade (Domingues, 2009a, cap. 1). As constituições têm sido consistentemente universalistas, mas os direitos coletivos dos povos originários e por vezes também das populações negras têm sido transplantados para dentro dos novos textos democráticos (Dávalos, 2005), por meio, em larga medida, dos giros modernizadores de "serialidades fechadas" enquanto subjetividades coletivas ativas e autoconstruídas.

Devemos acrescentar que a América Latina tem avançado exatamente naqueles lugares onde uma virtual conjunção entre movimentos sociais de todos os tipos tem logrado, direta ou indiretamente, realizar mudanças nas instituições e práticas, antes que permanecendo alheios ao sistema político, ao tentar preservar uma autonomia absoluta e quimérica (Adel Mirza, 2006; Svampa, 2008). Obviamente, o risco de cair nas mãos dos governos e inclusive nas da governamentalidade, na América Latina, em especial pelo clientelismo ou ao menos suportando quietamente administrações de esquerda, aumenta com a decisão de entrar mais diretamente no jogo político e engajar-se no plano das instituições. Contudo, novas redes, de colaboração efetiva e mais ampla, entre os movimentos, mas também entre eles e governos realmente democráticos, podem desdobrar-se disso (Maneiro, 2007; Domingues, 2009a, cap. 1; Domingues et alii, 2009). Escusado dizer que algumas vezes as coletividades dominantes se mantiveram no poder, outras vezes foram deslocadas por outras coletividades. A competição eleitoral funciona em toda a América Latina, e em parte se reestruturaram os sistemas de dominação burocrático-políticos.

O peronismo, o varguismo e o Estado mexicano, bem como as relações entre o campesinato e o Estado, depois da revolução boliviana de 1952 - em suma, o corporativismo em geral -, proveram os esquemas disciplinares mais fortes aplicados às classes trabalhadoras na América Latina (por vezes combinando a ação estatal com algum tipo de fordismo privado e outros tipos de ideologia, e apoiando-se talvez em elementos remanescentes das ideologias estatais coloniais). Enquanto esses esquemas perderam o suporte que um dia desfrutaram dessa armação 
corporativista e em muitos casos da transformação massiva das populações em trabalhadores e da absorção da disciplina industrial, eles têm sido continuamente, conquanto desigualmente, aplicados a toda a sociedade. Os esquemas disciplinares não têm recebido, contudo, um tratamento sintético no subcontinente (ao contrário, por exemplo, da China e do Sudeste Asiático em relação ao neodesenvolvimentismo e ao neoliberalismo, cf. Ong, 1999; 2006). No que tange ao "biopoder", este parece encontrar suas principais expressões nos esquemas sociais focalizados, vis-à-vis os programas sociais e as novas políticas derivadas originalmente dos programas compensatórios vinculados às "políticas de ajuste" (para uma visão geral destas últimas, ver Domingues, 2009a, caps. 1 e 3, embora não haja pesquisa sobre o biopoder ainda levada a cabo seriamente na América Latina, exceto no que se refere à administração das raças, seu branqueamento no início do século XX e sua miscigenação posteriormente). Mas o elemento de dominação presente em tais esquemas tem sido largamente ignorado pelos pesquisadores. Se é que seus avanços são decisivos, por outro lado a cidadania tem sido muito amiúde tomada de maneira acrítica como a solução de todos os problemas da região (por exemplo, em O'Donnell et alii, 2004).

\section{A Trajetória Brasileira}

O Brasil desdobrou ao longo do século XX o que alguns autores (Elisa Reis, Luiz Werneck Vianna, inspirados por Barrington Moore Jr.) caracterizaram como um processo de "modernização conservadora", originada de um acordo entre os grandes proprietários de terra e a burguesia industrial. Esse processo engendrou, a longo prazo, a industrialização, o fim das formas pessoais de dominação e o estabelecimento de uma "poliarquia" (no sentido de Dahl, 1971), isto é, liberdade de ir e vir, de vender a própria força de trabalho e de participar, a partir de meados dos anos 1980, do direito de voto, dos debates públicos e de manifestações, além, é claro, de eleições formalmente justas, apesar da violência contínua, endêmica, típica da história do país. A modernização conservadora se completou basicamente com a transição da ditadura militar (que foi sua última manifestação, autoritária, mas também industrializante) para o governo civil, eleito indiretamente em 1985, e com a promulgação, em 1988, de uma nova e progressista Constituição. Ampliação e pluralização da esfera pública foram igualmente um aspecto do processo. As eleições seguintes consolidaram a nova democracia, com suas virtudes e problemas (Domingues, 2004; Costa, 2002; Weyland, 2005). 
A participação popular tem sido bastante significativa, não obstante todas as restrições postas pelas profundas desigualdades e a falta de reconhecimento de largos setores da população, bem como, a despeito da extrema concentração dos meios privados de comunicação, o poder remanescente das oligarquias rurais regionais e os enclaves autoritários dentro do Estado ${ }^{3}$. Aquela revolução molecular democrática vem se desdobrando ao menos até recentemente (malgrado a longa onda de mobilização social que deslanchou nos anos 1970 haver se dissolvido já faz tempo). O Partido dos Trabalhadores (PT), mais uma vez ao menos originalmente, representou uma nova forma de combinar, em uma vasta rede de diferenças, movimentos sociais e política institucional, e sua ascensão ao poder representou uma ruptura (bastante) parcial com as políticas "transformistas" neoliberais que governos anteriores implementaram (Werneck Vianna, 1997; Domingues, 2009a, caps. 1 e 3). O Brasil compartilhou aquele mais amplo padrão de transição para a democracia com outros países latino-americanos: a transferência formal da soberania a seus cidadãos, no molde tradicional assinalado por liberais clássicos ou concepções "elitistas", assim como incluindo elementos apontados por discussões inovadoras sobre a sociedade civil, de qualquer modo, porém, muito distantes da compreensão de Foucault daquela noção como atinente tão somente ao poder de Estado - ainda que, para reiterar a questão, os sistemas de dominação tenham sido reestruturados.

No entanto, o caráter "despótico" de muito do Estado brasileiro não desvaneceu, e sistemas de dominação operam de maneira brutal em certas dimensões. As forças policiais tratam a criminalidade e as classes populares com frequência sem interesse ou então com extrema dureza; os direitos civis não são protegidos nesse sentido (embora o componente da propriedade certamente o seja!). Por outro lado, a pobreza continua sendo um problema generalizado, focalizado pelo governo Fernando Henrique Cardoso, em meados dos anos 1990, por meio de políticas compensatórias derivadas das políticas sustentadas pelo Fundo Monetário Internacional (FMI) e pelo Banco Mundial, e que acompanharam seus programas de "ajuste estrutural". Aquelas políticas se desdobraram na direção de programas de transferência de renda, levando enfim ao Bolsa Família, implementado pelo governo Luiz Inácio Lula da Silva. Esse programa alcançava mais de 11 milhões de famílias em 2009. Se, inicialmente, era possível ver nesses programas claramente uma maneira de "administrar" a pobreza, antes que eliminá-la (Lautier, 2004), o Bolsa Família tornou-se algo cuja definição é ex- 
tremamente difícil - questão tão mais curiosa quanto poucos estudos acadêmicos têm sido realizados acerca de seu funcionamento concreto, ao passo que o programa se converte no principal paradigma para a política social na América Latina (para visão geral e exploração de várias hipóteses, ver Kerstenetzky, 2009).

O Bolsa Família disponibiliza pequenas somas de dinheiro para domicílios com renda muito baixa como política focalizada que visa impedir os mais pobres entre os pobres de passar fome, idealmente os ajudando a sair dessa situação de miséria com duas "condicionalidades": acompanhamento médico e escolar de suas crianças. Seria ele basicamente um programa clientelista - por meio do qual o governo Lula ganha apoio entre os mais pobres -, que teria dado a Lula sua reeleição em 2006, ou se trata de um programa limpo baseado em critérios técnicos e sem interferências políticas, quase mobilizando uma filosofia calcada em direitos (Hunter e Power, 2007; Hilgers, 2008)? Trata-se sobretudo de uma política moderna que a longo prazo se converterá em uma renda básica do cidadão, ainda que hoje pudesse se confrontar com outros programas de transferência direta de renda (Lautier, 2006-2007; Domingues, 2009a, cap. 1)? Implica o programa uma estratégia econômica que ajuda a reforçar o mercado interno de bens não duráveis, uma espécie de keynesianismo dos pobres, ou é simplesmente uma maneira de lidar pragmaticamente com a enorme dívida que a sociedade brasileira tem com seus setores mais pobres a um custo muito baixo (Barros et alii, 2006; Domingues, 2009b)?

Martínez (2003:46-47) observou, em uma ocasião, provavelmente se apoiando na noção de "imaginário magmático" de Castoriadis (1975), que o peronismo na Argentina poderia ter qualquer significado através de inflexões sucessivas. Se isso não é exclusivo da América Latina (a política em particular e a vida humana em geral são constitucionalmente articuladas por essa flutuação magmática do sentido), as políticas não muito bem definidas ideologicamente dos partidos progressistas no poder, no subcontinente desde meados do século XX, levam isso bastante longe. Creio que, em certa medida, é o que ocorre com o Bolsa Família, o que significa também que sua direção futura não está ainda estabelecida. Penso que ele tem um componente de clientelismo que se encontra, contudo, distante do tipo "denso" que implica a troca de benefícios diretamente por votos, assim como das relações "cliente-patrono" que até recentemente tinham peso predominante na América Latina, com tipos bastante particularistas de vínculo de confiança - de 
resto o clientelismo mudou muito em todo o mundo (Eisenstadt e Roniger, 1984; Roniger, 2004). Creio que se encontra distante inclusive da versão "fina" do clientelismo, na qual essas relações são muito mais frouxas e o "cliente" é virtualmente autônomo, de modo absoluto, para tomar decisões eleitorais.

"Clientelismo burocrático" foi como o denominei. Não estamos falando de um direito, de maneira alguma, embora realmente muitos estejam inclinados a empurrar o programa nessa direção, sendo possível que isso ocorra no futuro. No entanto, tal leitura não pode ser feita no presente, pois se trata de um benefício concedido de cima para baixo, como política social condicional (a saber, miséria e comportamento regulado), sem armação constitucional (embora gravada na legislação ordinária congressual), envolvendo algum tipo de dependência e aliança política frouxa (Domingues, 2009a:45-54) ${ }^{4}$. Deve-se acrescentar que, dadas as circunstâncias, o Bolsa Família tem enormes méritos. Obviamente não é de modo nenhum irracional que as "massas" o sustentem eleitoralmente: ele de fato contribui seriamente para a redução da miséria. Tem ademais funcionado como uma maneira de desenvolver alguns aspectos do mercado interno. Contudo, o que quero explorar neste artigo é antes o caráter focalizado e particularista do programa (no momento, a bem dizer), que implica um tipo específico de "subjetividade coletiva", ou seja, uma serialidade agudamente fechada - a vasta serialidade fechada e passiva dos muito pobres. Ela é estabelecida estatística e econometricamente, embora na base os comitês locais tenham um importante papel a cumprir. Além disso, do ponto de vista dos beneficiários, a bolsa é recebida de cima para baixo, embora as raízes do programa se encontrem em uma mobilização social ampla (conquanto não principalmente por parte dos setores mais pobres da população) e na constante tematização da questão da pobreza em debates públicos que tiveram lugar desde ao menos o começo dos anos 1990. Antes de seguir adiante, gostaria de desenvolver uma curta digressão teórica.

A cidadania nasceu no Ocidente, por meio dos direitos civis, originalmente como uma forma de assegurar a vida dos indivíduos, garantindo seus títulos de propriedade, a base do capitalismo e das classes sociais modernas. Os direitos políticos eram vistos como uma maneira de controlar o Estado, uma nova entidade formada pelo contrato geral dos cidadãos, que assim transferiam ao Estado sua soberania. Uma liberdade igualitária universalista subjazia a essa definição, especialmente no que concerne ao deslocamento pessoal dentro de um território 
nacional e à possibilidade de estabelecer contratos, embora os pobres de modo geral, simplesmente as classes trabalhadoras - tenham sido postos em posição muito mais problemática desde o começo, no que se refere ao feixe de direitos políticos. A burguesia não ganhou esses direitos sem luta (e sem, às vezes, perigosas alianças com o proletariado, e com compromissos evidentemente com as classes dominantes agrárias fazendo parte do processo também). Os direitos sociais foram introduzidos para corrigir a exclusão das classes trabalhadoras dos benefícios da modernidade, da economia de mercado e para facilitar sua inclusão na vida social, de modo que aquela liberdade pudesse ser realmente desfrutada. Se, em alguns momentos, houve movimentos preventivos do Estado em relação às classes trabalhadoras nesse sentido, e havia algumas preocupações biopolíticas na base da criação dos Estados do Bem-Estar Social europeus, esses direitos foram duramente conquistados, por vezes em lutas ferozes, em um processo histórico dilatado. $\mathrm{O}$ contraste entre a situação atual, mesmo na Europa, e aquela dos anos 1960-1970 deveria nos alertar para isso. A princípio, os direitos sociais tendiam a ser vistos também como universais, conquanto a questão do particularismo surgisse desde o começo e os sistemas "corporativistas" criassem ainda outros problemas. Direitos implicavam o que chamei de "abstrações reais", à medida que os cidadãos individuais, em sua universalidade e falta de qualidades específicas, a eles tinham franquia; com, além disso, a própria estrutura da vida social tornando-se, em larga medida, determinada por seu estabelecimento. Eles implicavam também o elemento "instituinte" da cidadania, muito embora, ao serem conquistados, esses direitos tenham se convertido no que pode ser chamado de cidadania "instituída", ao lado da entrega da soberania ao Estado, que agora se depara com cidadãos passivos. Isso se agrava com o fato de que os direitos sociais são, em grande medida, implementados por um corpo burocrático (Domingues, 2002, caps. $2-4)$.

Tudo isso é verdadeiro, mas a complexidade do processo desapareceu da descrição de Chatterjee acima e está ausente de sua crítica excessivamente rápida a Marshall. Por outro lado, na América Latina, a cidadania civil tem sido contemplada de maneira benigna demais, como se a dominação e a desigualdade, por intermédio da propriedade e das relações de trabalho capitalistas, não fossem introduzidas precisamente por ela desde as constituições do século XIX; e a cidadania política, com a cessão formal (e, ademais, certamente ideológica) da soberania, não legitimasse a existência do sistema de dominação estatal que mes- 
mo autores como Habermas não podem deixar de reconhecer (para não falar de Marx e Weber, Poulantzas, Foucault e Mann) (Domingues, 2009a, caps. 1 e 3). No Brasil, a Constituição de 1988 abraçou precisamente essa concepção universalista dos direitos, em todas as suas dimensões. Se não se concretizaram, é possível afirmar, como fazem alguns, que o texto traçou um "programa" para a sociedade brasileira (Oliven, Ridenti e Brandão, 2008). Destarte, foi sobretudo uma serialidade aberta que se pôs nas bases da Constituição de 1988 (não obstante proteções específicas para uns poucos grupos específicos). É exatamente com esse núcleo de universalismo nacional que o Bolsa Família e sua serialidade fechada, com sua biopolítica e leves propósitos disciplinares (mediante condicionalidades), efetivamente rompem, a despeito de assertivas de que no futuro o programa pode levar a uma renda básica cidadã - a uma serialidade aberta. $O$ fato de que condicionalidades não parecem ser severamente vigiadas não muda o cerne do Bolsa Família.

Uma questão adicional deve ser tratada aqui. Chatterjee fala da "política dos governados" como implicando não passividade, mas sim um alto nível de atividade para seus realizadores. Com efeito, encontramos isso no Brasil também, por exemplo, e talvez, acima de tudo (na verdade, de modo similar em parte ao que ele mesmo narra para a Índia), no que diz respeito aos graves problemas dos assentamentos ilegais das cidades, as favelas. Estas têm consistido em áreas de preocupação do Estado, de poder disciplinar e biopolítico (com seus peritos e agora amiúde por meio de organizações não governamentais ONGs). Há nesse sentido limitações no que tange a políticas concretas (provavelmente isso ocorre igualmente na Índia), uma vez que laços informais são fortes e escapam da visão do Estado. Por vezes atenção é dirigida às favelas sem atuação coletiva imediata por parte de seus moradores, mas há uma longa história de mobilização pacífica e de criação de associações representativas, bem como de revoltas, além de guerra de fato entre traficantes de drogas e entre eles e a polícia, por exemplo, nas favelas do Rio de Janeiro (ver Valladares, 2005). A serialidade fechada implicava atividade nesse sentido. Esse não é, porém, o caso do programa Bolsa Família, no qual a serialidade fechada significa passividade - exceto talvez quando chega a hora de votar -, sem o universalismo e os direitos do conceito da "cidadania instituída".

É verdade que serialidades fechadas são, em certa medida, inevitáveis, tendo permanecido assim desde ao menos que a cidadania social aden- 
trou a cena, visto que ela dificilmente permite um universalismo consistente e completo, com os problemas que a colonização da vida social pelos corpos burocráticos que têm sido tão centrais para o Estado do Bem-Estar nos força a encarar (cf. Habermas, 1981). É verdade ainda que a heterogeneidade da vida social e a pluralidade de identidades das subjetividades coletivas têm crescido tremendamente na atual fase da modernidade, a terceira, que inclui um espaço-tempo igualmente mais heterogêneo ${ }^{5}$, para além das possibilidades que o mercado e o Estado um dia desfrutaram de homogeneizar o tecido social - fenômeno que pertence tanto ao centro quanto às periferias e semiperiferias da modernidade global (Domingues, 2002; 2009a). Contudo, devemo-nos pôr a questão: isso significa que temos de replicá-la nos arranjos da política social ou será que podemos perseguir algum tipo de perspectiva universalista também nesse sentido, enquanto nos esforçamos para dar novo sentido à cidadania civil e revigorar a cidadania política? Apesar das limitações, é dentro do imaginário da modernidade, com suas demandas universalizantes de liberdade igualitária, solidariedade e responsabilidade, contra a dominação, a desigualdade e a fragmentação, ao que se agrega uma concepção de responsabilidade, para além do egoísmo neoliberal, que a América Latina vem avançando nos últimos anos. A cidadania está em larga medida instituída. A atividade dos cidadãos se faz, todavia, necessária para ampliá-la, bem como para evitar que decaia na soberania sem peias dos grupos dominantes do Estado e da burocracia. Dever-se-ia escolher um caminho sobretudo particularista?

Cada região, na modernidade global, tem suas próprias raízes civilizatórias, e é bastante evidente que as da Índia diferem enormemente das da América Latina. Essas questões ventilam, porém, mais do que temas regionais. Embora se possa também afirmar que o Estado vem se tornando mais duro e violento na Índia, podemos singularizar a atitude original de acomodação do centro a uma pluralidade de demandas de outros setores da sociedade como típica desse país do sul da Ásia (Nandy, 2002, caps. 3-4; Eisenstadt, 2003), engendrando o particularismo (seja por meio da serialidade das castas reestruturadas, seja por questões mais circunscritas), embora o universalismo da Constituição indiana de 1949 seja bastante óbvio (não obstante proveja em si defesas particularistas para os setores destituídos da população, em especial as castas inferiores). Podemos talvez contrastar isso com o imaginário moderno latino-americano, mais universalista, conquanto de modo mais geral a região não tenha sido palco de divisões ideológi- 
cas agudas (em contraposição a ferozes batalhas sociais e políticas) e tenha tido como ideologia de Estado, em muitos períodos, a integração de todos na nação. Tanto o tema da heterogeneidade quanto as demandas de universalismo e soberania popular - para além de reações àqueles que governam ou da simples afirmação de demandas que, na Índia, têm, por meio de demonstrações violentas, mas sem consequência, com frequência assumido uma forma ritual em vez de demonstrar cunho substantivo (Chakrabarty, 2007) - são, sem embargo, hodiernamente inescapáveis em ambos os subcontinentes. Ademais, aqueles que estão incluídos na cidadania formal, no que se refere aos direitos políticos, e demandam direitos civis e por vezes sociais são os mesmos que (passando diariamente de uma dimensão a outra) compartilham laços informais e podem tornar-se, de uma forma ou de outra, mais passiva ou ativamente, os alvos de políticas focalizadas.

\section{CONCLUSÃO: DE VOLTA À TEORIA, DE VOLTA À DEMOCRACIA}

Chatterjee visa que sua contribuição, de modo foucaultiano, deixe para trás discussões sobre dominantes (rulers) e dominados (ruled), debruçando-se sobre aqueles que governam e aqueles que são governados. Não quero entrar em disputas semânticas. Basta dizer que não consigo ver muita diferença na formulação, uma vez que aqueles que governam o fazem porque dominam, e aqueles que são governados o são porque, por sua vez, são dominados. Por outro lado, a dominação é possível em uma sociedade complexa tão somente na medida em que aqueles que estão por cima podem governar, moldando a subjetividade e os modos de vida dos que estão por baixo, por meio do poder "infraestrutural", ou seja, de modo mais sofisticado e sutil que o uso do puro poder "despótico". É certo que a "produtividade" do poder, para além de seus aspectos repressivos (embora obviamente não os desconsiderando), deve ser central para uma análise das hierarquias e da dominação na vida social moderna. Nesse sentido, como Foucault demandava, carecemos de uma política que vá além do Estado e do momento da soberania, visto que o poder se espraia pelo tecido social. No entanto, carecemos também de uma política para além do poder do Estado no sentido ascendente, globalmente, isto é, considerando que as sociedades não são autocontidas, como logo argumentarei em termos mais concretos.

Contudo, ao passo que o poder das corporações e do capitalismo de maneira geral (ou de brancos e homens) permanece formidável no pla- 
no societal, e a emancipação não pode ser completa se as corporações e o capitalismo não são radicalmente enfrentados, o Estado é um lócus de poder - e de luta - que segue sendo extremamente importante na modernidade contemporânea. É ainda, em alto grau, o centro da vida política, ao contrário da posição quase luhmanniana de Habermas, na qual a esfera pública e a sociedade o deslocariam de algum modo, diminuindo sua relevância. Não vejo evidência empírica disso. Na verdade, embora a democratização seja fato com significado profundo na América Latina, e o fortalecimento e a pluralização da esfera pública venham cumprindo papel vital, é em outra direção que o descentramento do Estado nacional vem ocorrendo. Organizações internacionais - como o FMI e o Banco Mundial, bem como poderosos governos centrais e as "agências de avaliação de risco" - têm forçado políticas que sistematicamente passam ao largo de discussões democraticamente encetadas, como podemos testemunhar, por exemplo, no caso da América Latina (Domingues, 2009a, cap. 2) e da África (Ferguson, 2006 , cap. 4). Se na primeira isso foi revertido em certa medida mais recentemente, na segunda o descentramento do Estado é ainda mais radical e tem ocorrido sem uma revolução democrática molecular que o acompanhe, fazendo assim da democracia quase que uma casca oca em grande parte do continente africano.

É possível e desejável reafirmar a necessidade de um Estado nacional mais forte nesse sentido? Creio que sim, mas esse não é exatamente o ponto que quero fazer aqui. Na verdade, quero dividir essa questão e fazê-la mais condicional a uma concepção mais profunda do significado da democracia, que pode, como afirmado no início deste artigo, apontá-la como um baluarte contra a dominação. Necessitamos o império da lei, necessitamos a cidadania instituída; necessitamos serialidades de caráter aberto e fechado (não é preciso dizer, em especial as primeiras) que estejam consagradas no direito constitucional ou infraconstitucional, bem como em arranjos burocráticos, oxalá para além de qualquer forma de clientelismo - denso, fino ou burocrático. Em outras palavras, necessitamos o Estado e seus aparatos, uma vez que não sabemos como nos livrarmos dele mais do que sabemos como nos livrarmos do capitalismo (embora mais recentemente venhamos aparentemente confiando em nossa capacidade de dar cabo do racismo e da patriarquia). Contudo, se podemos pensar no Estado em certa medida representando, por meio do direito, dos funcionários públicos e dos políticos, a vontade do povo, agora preso à passividade, como cidadania instituída, devemos estar cientes do fato de que, uma vez que 
a soberania é cedida aos funcionários e aos políticos, a semente da dominação é inevitavelmente semeada. Habermas está atento para isso e reconhece um sistema político poderoso, autônomo e autorreferido, mas parece crer que a mera agregação da "democracia deliberativa" como outra dimensão da política resolve o problema. Não resolve. Foucault e Chatterjee estão corretos nesse sentido. No entanto, não podemos escolher apenas a resistência ou os aspectos extrainstitucionais da política para chegar a mais democracia, como o último deles sugere. A política da soberania ainda tem um papel a cumprir contra a dominação. É óbvio que a Índia não é a América Latina e que seria exagerado e abusivo julgar aqui a política daquele país - conquanto não possamos tratar levianamente nem sua tradição constitucional nem a força que a democracia tem continuamente demonstrado ali. Fato é que o desenvolvimento democrático paulatino da América Latina tem incluído ambas as dimensões da política que Chatterjee descreve como aquelas das sociedades civil e política. Contudo, a questão particularismo versus universalismo não é simples de solucionar, é algo que se expressa significativamente, por um lado, pela emergência (e, esperemos, pela queda) do chauvinismo do Hindutva na Índia e, por outro, pelas demandas étnicas democratizantes em toda a América Latina. O nacionalismo pode, de maneira mais abrangente e abstrata, reconciliar e superar essas duas possibilidades de desenvolvimento? Isso é improvável e compromissos têm de ser de algum modo alcançados, como a Índia tem com efeito buscado desde sua independência, enquanto na América Latina, não obstante o corporativismo, apenas mais recentemente essa questão se tem posto de maneira frontal.

O Estado precisa ser, portanto, recolonizado pela sociedade, de forma que se torne mais representativo da vontade popular; precisa de coalizões populares que possam mudar a face da modernidade contemporânea para além do neoliberalismo, da fragmentação, da administração da pobreza, bem como das situações radicais da política étnica e religiosa. Este é o momento da democracia instituinte - nesse sentido, também participativa, seja lá como a divisemos - como autolimitante no que se refere à garantia de liberdade para qualquer um debater e discordar, de maneira geral mantendo-se o império da lei; é o momento da democracia constitucional, com seus elementos de cidadania instituída. Obviamente, a etnicidade radical milita precisamente contra essa autolimitação e contra a liberdade igualitária que a democracia em parte pressupõe e deveria produzir, quaisquer que sejam os mecanismos institucionais e os resultados substantivos que deve mobilizar 
para isso. Seja como for, a desobediência civil deveria ser vista como um modo legítimo da política, inclusive em democracias constitucionais bem-estabelecidas, e não deveria haver razão para os movimentos sociais sustentarem qualquer "fetichismo legal", destarte por vezes combinando giros legais e ilegais (em princípio pacíficos, se vivemos em uma democracia) para atingir suas metas (Santos, 2007:97-98). Todavia, é mister termos em mente também que não deveria haver razão para que os movimentos sociais limitassem o alcance de suas opções à "sociedade civil" na tradição habermasiana, como se a política propriamente dita fosse espaço privilegiado de uma "elite" específica ou como se eles nela pudessem se poluir e a seu mundo da vida. A América Latina tem realmente uma tradição de ir além disso, seja no sistema corporativista dos anos 1930-1960, seja hoje, nas relações em rede entre os movimentos sociais, os partidos e os Estados que assinalei anteriormente. É evidente que o risco de cooptação sempre se insinua, mas parece que os movimentos sociais têm de encará-lo a fim de se aprofundar no sistema político e impulsionar mudanças que respondam a seus programas (ver Domingues, 2007, cap. 6).

Isso nos leva a uma questão final: a representação. Não pretendo retomar um debate já longo e algo tedioso que vem se desenvolvendo há alguns anos e se relaciona com a óbvia crise da representação, de modo geral, e em particular com a falta de credibilidade dos partidos políticos. Enquanto a América Latina tem recentemente mostrado que eles podem ser produtivos, em muitos casos, na vida democrática, se expressam a renovação da vida social, essa forma bem pode revelar falhas que a fazem problemática para a expressão de uma gama complexa de questões e subjetividades coletivas na modernidade contemporânea. Além disso, os partidos políticos - assim como os movimentos sociais - sofrem dos mesmos males que os sistemas políticos, nomeadamente, a cristalização de coletividades dominantes (ou governantes) que terminam por estabelecer sistemas de dominação. Estes são, contudo, os canais de representação que temos na sociedade contemporânea, e o corte do laço entre representação e autorização (para representar) parece altamente problemático e perigoso a essa altura, seja em relação às organizações da "sociedade civil" (como ONGs, na verdade corpos burocráticos privados) e causas públicas (Avritzer, 2007), seja como corpos estatais e a dita "representação funcional", como no caso do Ministério Público brasileiro (Werneck Vianna et alii, 1999). A mediação, em particular no que concerne a direitos e a questões "difu- 
sas", segue sendo o melhor caminho para observar a contribuição desses agentes aos processos democráticos.

De todo modo, a cidadania instituída permanece como questão-chave para a vida democrática, com a atividade das subjetividades coletivas, sua concretude e seus giros modernizadores, de inspiração mais universalista ou mais particularista, em oposição à dominação, à reificação e à passividade. A democracia floresce ou decai dependendo da dinâmica da cidadania instituinte. Nesse processo, embora em si mesmas não sejam o bastante nem ademais deem cabo dos grupos políticos dominantes e autorreferentes (as chamadas "elites"), a extensão das instituições "poliárquicas" têm evidentemente papel importante a cumprir, permitindo a discussão racional livre (logo a constituição e a ampliação das esferas públicas), bem como a participação e a ampliação do direito de voto. Giros modernizadores defensivos, no sentido de manter certos aspectos da democracia ante poderosas subjetividades coletivas estatais, dependem, em grande medida, da cidadania instituída e instituinte, assim como o fazem giros que tencionam ir além do presente estado da democracia em qualquer parte do mundo, seja deslanchados pelo que podem se tornar em estágios ulteriores serialidades abertas, seja por serialidades fechadas. Eis o caminho, creio, pelo qual a democracia liberal pode corresponder, desafiada e transformada, a suas promessas originais e pelo qual a liberdade, no que tange aos sistemas políticos, pode ainda ter chance contra a dominação. Essa é a forma pela qual a teoria crítica pode permanecer crítica, realista e engajada com a democracia. Isso é verdade tanto no que tange aos países centrais quanto no que se refere à periferia e à semiperiferia, pois são questões que, com peculiaridades e características específicas, concernem à situação da democracia nas sociedades altamente complexas da terceira fase da modernidade.

No entanto, aqui devemos pausar com sobriedade, pois à democracia e à cidadania se tem com frequência pedido mais do que podem produzir. Podemos e devemos desafiar a democracia liberal a avançar para além de seus limites. Todavia, há outros sistemas de dominação com que temos de nos engajar, tais como o capitalismo, a patriarquia, de dominação étnica e racial (nesse caso, nos planos econômico e social também). Mesmo o avanço da democracia depende da espécie de cidadão que lhe empresta suporte. Este deriva de uma ampla gama de relações sociais, às quais não se deve permitir que desapareçam nas sombras. Essas relações não têm sido capazes de quebrar o desenvolvimento da 
democracia na América Latina, em tempos recentes, nem na Índia, como muitos não sem razão temeram, embora o Ocidente tenha um registro de longo prazo que demonstra os limites da democracia e da "sociedade civil" quando o poder é tão desigualmente distribuído. Seja como for, decerto essas desigualdades são, para não avançar demasiado, elementos que não contribuem para o desenvolvimento da democracia e certamente lhe impõem barreiras. Uma tensão crucial e iniludível da modernidade radica aqui.

(Recebido para publicação em maio de 2009)

(Versão definitiva em setembro de 2009)

\section{NOTAS}

1. De qualquer forma, o nacionalismo é um inimigo antigo para Chatterjee (1986; 1993). Para discussão suplementar sobre a democracia na Índia, ver Jayal (2007).

2. A esfera pública - abarcando não apenas a chamada ação comunicativa, mas todas as formas de coordenação da ação, incluindo o mercado, a hierarquia e as redes - se destacará na descrição a seguir da democratização, antes da sociedade civil. Essa noção é demasiadamente vaga, não obstante sua importância em discussões-chave sobre a democracia e a democratização na América Latina. Não creio que seja aceitável nos quadros adaptados de Cohen e Arato ou do Habermas tardio, pois ela não se encaixa realmente na teoria geral deste último (Habermas, 1981), consistindo em uma manobra ad hoc. Por seu turno, o antigo uso gramsciano na verdade aponta sobretudo para a sociedade em seu conjunto, mesmo se ele não sublinha a dimensão econômica que era tão central para o "sistema das necessidades" em Hegel. Deve-se, contudo, observar que, para um tipo de discussão que não desenvolverei neste artigo, o conceito paralelo de "hegemonia" é ainda de imenso valor; e, obviamente, associações de todos os tipos são cruciais para o estado da democracia.

3. Essa falta de reconhecimento implica uma condição de "subcidadania" para largos setores da população brasileira (cf. Souza, 2003)? Há um problema real aqui, porquanto as condições sociais que contribuem para os cidadãos concretos têm de ser levadas em conta - e elas são deficientes em todo o mundo, mas em particular em sociedades em que as desigualdades estão profundamente enraizadas, como é o caso do Brasil. Por outro lado, a cidadania instituída é, em grande medida, formal e devemos, por conseguinte, ser cuidadosos para não estender excessivamente o alcance daquela reserva, já para não falar da mobilização instituinte, de enorme impacto, da população brasileira nas últimas décadas.

4. Em 8 de janeiro de 2004, a Lei da Renda Básica de Cidadania, por longo tempo uma bandeira do senador Eduardo Suplicy, foi aprovada, mas não há recursos para sua 
implementação, embora Suplicy e o governo, o próprio presidente na ocasião, a tenham vinculado ao Bolsa Família, criado em 9 de janeiro de 2004, pela Lei 10.836, como meio de dar molde formal ao aspecto específico, mais limitado, do programa conhecido como Fome Zero. Beneficiários focalizados (por nível de renda) e condicionalidades são claramente definidos por lei (ajustada em 10 de junho de 2008, pela Lei 11.692). Por seu turno, o volume de recursos disponíveis e o número de beneficiários são definidos, de acordo com a lei, pelo governo em relação aos recursos disponíveis no orçamento. Desde então não houve nenhuma movimentação no sentido de transformar o Bolsa Família em um esquema de renda básica.

5. Chatterjee (2004, em especial p. 8) está parcialmente correto a esse respeito, embora antes do capital e meramente do espaço social devêssemos falar do espaço homogêneo, vazio, abstrato e paramétrico (kantiano-newtoniano) da cidadania e de suas "abstrações reais" em contraste com o (pós-einsteiniano) espaço-tempo desigual, concreto, heterogêneo, pleno de relações sociais e afetos que é característico dos reencaixes concretos da modernidade (que podem assumir forma serial fechada) (Domingues, 2002, cap. 4). É verdade, contudo, que a dinâmica expansiva do capital tem sido crucial e particularmente importante na disseminação das "abstrações reais" pelo mundo, afora o Ocidente (e a América Latina também).

\section{REFERÊNCIAS BIBLIOGRÁFICAS}

ADEL MIRZA, Christian. (2006), Movimientos Sociales y Sistemas Políticos en América Latina. Buenos Aires, Clacso.

ALEXANDER, Jeffrey A. (2006), The Civil Sphere. Oxford/New York, Oxford University Press.

ANDERSON, Benedict. (1998), The Spectre of Comparisons: Nationalism, Southeast Asia, and the World. London, Verso.

AUYERO, Javier. (2001), La Política de los Pobres: Las Prácticas Clientelares del Peronismo. Buenos Aires, Manantial.

AVRITZER, Leonardo. (2002), Democracy and the Public Space in Latin America. Princeton, Princeton University Press.

. (2007), "Sociedade Civil, Instituições Participativas e Representação: da Autorização à Legitimidade da Ação". DADOS, vol. 50, no 3, pp. 443-464.

e COSTA, Sérgio. (2005), “Teoria Crítica, Democracia e Esfera Pública”, in J. M. Domingues e M. Maneiro (orgs.), América Latina hoje. Conceitos e Interpretações. Rio de Janeiro, Civilização Brasileira.

BARRIENTOS, Armando. (2004), “Latin America: Towards a Liberal-Informal Welfare Regime", in I. Gough e G. Wood (eds.), Insecurity and Welfare Regimes in Asia, Africa and Latin America. Cambridge, Cambridge University Press. 


\section{Democracia e Dominação: Uma Discussão (via Índia) com Referência...}

BARROS, Ricardo et alii. (2006), “Uma Análise das Principais Causas da Queda Recente da Desigualdade de Renda no Brasil". Econômica, vol. 8.

CASTORIADIS, Cornelius. (1975), L'Institución Imaginaire de la Société. Paris, Seuil. (1999), "Quelle Democratie?", in C. Castoriadis, Figures du Pensable, VI. Paris, Seuil.

CHAKRABARTY, Dipesh. (2007), "'In the Name of Politics': Democracy and the Power of the Multitude in India", in D. Chakrabarty, R. Majumdar e A. Sartori (eds.), From the Colonial to the Postcolonial. India and Pakistan in Transition. Oxford, Oxford University Press.

CHATTERJEE, Partha. (1986), Nationalist Thought and the Colonial World. A Derivative Discourse. Minneapolis, University of Minneapolis Press.

(1993), The Nation and its Fragments. Colonial and Postcolonial Histories. Princeton, Princeton University Press.

. (1998), "Secularism and Toleration", in P. Chatterjee, A Possible India. Essays in Political Criticism. Nova Delhi, Oxford University Press.

. (2004), The Politics of the Governed. Reflections on Popular Politics in Most of the World. New York, Columbia University Press.

. (2008), “Gramsci nel Ventunesimo Secolo". Studi Culturali, no 2.

COHEN, Jean e ARATO, Andrew. (1992), Civil Society and Political Theory. Cambridge, MIT Press.

COSTA, Sérgio. (2002), As Cores de Ercília. Esfera Pública, Democracia, Configurações Pós-Nacionais. Belo Horizonte, Ed. UFMG.

DAHL, Robert. (1971), Poliarchy: Participation and Opposition. New Haven, Yale University Press.

DÁVALOS, Pablo (org.). (2005), Pueblos Indígenas, Estado y Democracia. Buenos Aires, Clacso.

DOMINGUES, José Maurício. (2002), Interpretando a Modernidade. Imaginário e Instituições. Rio de Janeiro, Editora FGV.

. (2004), "A Dialética da Modernização Conservadora e a Nova História do Brasil", in J. M. Domingues, Ensaios de Sociologia: Teoria e Pesquisa. Belo Horizonte, Ed. UFMG.

. (2007), Aproximações à América Latina. Desafios Contemporâneos. Rio de Janeiro, Civilização Brasileira.

. (2009a), A América Latina e a Modernidade Contemporânea. Uma Interpretação Sociológica. Belo Horizonte, Ed. UFMG.

(2009b), "Desenvolvimento e Dependência, Desenvolvimentismo e Alternativas". Ponto de Vista, no 3.

e MANEIRO, María. (2007), "Revisitando Germani: A Interpretação da Modernidade e a Teoria da Ação", in J. M. Domingues, Aproximações à América Latina. Desafios Contemporâneos. Rio de Janeiro, Civilização Brasileira.

DOMINGUES, José Maurício et alii (orgs.). (2009), A Bolívia no Espelho do Futuro. Belo Horizonte, Ed. UFMG. 
EISENSTADT, Shmuel N. (1999), Paradoxes of Democracy. Fragility, Continuity, and Change. Washington, D.C./London/Baltimore, Woodrow Wilson/Johns Hopkins University Press.

. (2003), "The Puzzle of Indian Democracy", in S. N. Eisenstadt, Comparative Civilizations and Multiple Modernities. Leiden, Brill.

e RONIGER, Luis. (1984), Patrons, Clients and Friends. Interpersonal Relations and the Structure of Trust in Society. Cambridge, Cambridge University Press.

FERGUSON, James. (2006), Global Shadows. Africa and the Neoliberal World Order. Durham, NC/London, Duke University Press.

FOUCAULT, Michel. (1979), "A Governamentalidade”, in M. Foucault, A Microfísica do Poder. Rio de Janeiro, Graal. . (1997) [1976], Il Fault Défendre la Société. Paris, Seuil.

FOX, Jonathan. (1997), “The Difficult Transition from Clientelism to Citizenship: Lessons from Mexico", in D. A. Chalmers et alii (eds.), The New Politics of Inequality in Latin America. Rethinking Participation and Representation. Oxford, Oxford University Press.

GARCÍA LINERA, Álvaro. (2004), “Democracia Liberal versus Democracia Comunitaria". El Juguete Rabiosa, ano 3, no 96.

HABERMAS, Jürgen. (1981), Theorie des Kommunikativen Handelns, vols. 1-2. Frankfurt am Main, Suhrkamp.

. (1990), Die Nachholende Revolution. Frankfurt am Main, Suhrkamp.

. (1992), Faktizität und Geltung. Frankfurt am Main, Suhrkamp.

HAGOPIAN, Frances. (2005), “Conclusion. Government Performance, Political Representation, and Public Perceptions of Contemporary Democracy", in F. Hagopian e S. Mainwaring (eds.), The Third Wave of Democratization in Latin America. Advances and Setbacks. Cambridge, Cambridge University Press.

HILGERS, Tina. (2008), “Causes and Consequences of Political Clientelism: Mexico's PRD in Comparative Perspective". Latin American Politics and Society, vol. 50, no 4, pp. 123-153.

HUNTER, Wendy e POWER, Timothy J. (2007), “Rewarding Lula: The Brazilian Elections of 2006". Latin American Politics and Society, vol. 49, no 1, pp. 1-30.

JAYAL, Nijara Gopal (ed.). (2007), Democracy in India. Nova Delhi, Oxford University Press.

KERSTENETZKY, Celia Lessa. (2009), “Redistribuição $e$ Desenvolvimento? A Economia Política do Programa Bolsa Família”. DADOS, vol. 52, no 1, pp. 53-83.

LAUTIER, Bruno. (2004), “Les Politiques Sociales au Mexique et au Brèsil: 1'Assurance, l'Assistance, 1'Absence", in B. Lautier e J. M. Pereira (eds.), Brèsil, Mexique: Deux Trajectories dans la Mondialisation. Paris, Karthala.

(2006-2007), “Les Politiques Sociales au Brasil durant le Gouvernement de Lula: Aumône d'État ou Droits Sociaux". Problèmes d'Amérique Latine, no 63. 
MAINWARING, Scott e HAGOPIAN, Frances. (2005), "Introduction. The Third Wave of Democratization in Latin America", in F. Hagopian e S. Mainwaring (eds.), The Third Wave of Democratization in Latin America. Advances and Setbacks. Cambridge, Cambridge University Press.

MAINWARING, Scott e PÉREZ-LIÑAN, Aníbal. (2005), “Latin America Democratization since 1978. Democratic Transitions, Breakdowns, and Erosions", in F. Hagopian e S. Mainwaring (eds.), The Third Wave of Democratization in Latin America. Advances and Setbacks. Cambridge, Cambridge University Press.

MANEIRO, María. (2007), Encuentros y Desencuentros. Estado y Movimientos de Trabajadores Desocupados del Gran Buenos Aires (1996-2005). Tese de doutorado, IUPERJ, Rio de Janeiro.

MANN, Michael. (2006), “A Crise do Estado-Nação Latino-Americano”, in J. M. Domingues e M. Maneiro (orgs.), América Latina Hoje. Conceitos e Interpretações. Rio de Janeiro, Civilização Brasileira.

MARTÍNEZ, Tomás Eloy. (2003), Requien por un País Perdido. Buenos Aires, Aguilar.

MÉNDEZ, Juan, O’DONNELL, Guillermo e PINHEIRO, Paulo Sérgio (orgs.). (2003), La (In)Efectividad da Ley y la Exclusión en América Latina. Buenos Aires, Paidós.

NANDY, Ashis. (2002), Time Warps. Silent and Evasive Pasts in Indian Politics and Religion. New Brunswick, Rutgers University Press.

O'DONNELL, Guillermo. (1994), “Delegative Democracy". Journal of Democracy, vol. 5. . (1996), "Illusions about Consolidation". Journal of Democracy, vol. 7.

et alii. (2004), La Democracia en América Latina. Hacia una Democracia de Ciudadanos y Ciudadanas. Buenos Aires, PNUD.

OLIVEN, Ruben George, RIDENTI, Marcelo e BRANDÃO, Gildo Marçal (orgs.). (2008), A Constituição de 1988 na Vida Brasileira. São Paulo, Hucitec.

ONG, Aihwa. (1999), Flexible Citizenship. The Cultural Logics of Transnationality. Durham/ London, Duke University Press.

. (2006), Neoliberalism as Exception. Mutations in Citizenship and Sovereignty. Durham/ London, Duke University Press.

RONIGER, Luis. (2004), "Political Clientelism, Democracy and Market Economy". Comparative Politics, vol. 36 .

. (2005), “Global Times once Again: Representative Democracy and Countervailing Trends in Iberoamerica". Iberoamericana, vol. 17.

ROSE, Nicolas. (1999), Powers of Freedom. Reframing Political Thought. Cambridge, Cambridge University Press.

SANTOS, Boaventura de Sousa. (2007), Renovar a Teoria Crítica e Reinventar a Emancipação Social. São Paulo, Boitempo.

SOUZA, Jessé. (2003), A Construção Social da Subcidadania. Para uma Sociologia Política da Modernidade Periférica. Belo Horizonte, Ed. UFMG.

SVAMPA, Maristella. (2008), Cambio de Época. Movimientos Sociales y Poder Político. Buenos Aires/México, Clacso/Siglo XXI. 
José Maurício Domingues

VALLADARES, Licia. (2005), A Invenção da Favela. Do Mito de Origem à Favela.com. Rio de Janeiro, Editora FGV.

WEBER, Max. (1980) [1921-1922], Wirtschaft und Gesellschaft. Tübingen, J. C. B. Mohr [Paul Siebeck].

WERNECK VIANNA, Luiz. (1997), A Revolução Passiva. Iberismo e Americanismo no Brasil. Rio de Janeiro, Revan.

et alii. (1999), A Judicialização da Política e das Relações Sociais. Belo Horizonte, Ed. UFMG.

WEYLAND, Kurt. (2005), “The Growing Sustainability of Brazil's Low Quality Democracy", in F. Hagopian e S. Mainwaring (eds.), The Third Wave of Democratization in Latin America. Advances and Setbacks. Cambridge, Cambridge University Press. 


\begin{abstract}
Democracy and Domination: A Discussion (via India) with Reference to Latin America (Brazil)

Universalism and particularism have become essential structural issues for modern thought and lead to distinct definitions of democracy, citizenship, and social policy. Challenging Habermas and the Habermasians, the current article argues that democracy can never be identified with domination. Meanwhile, contesting Chatterjee and Foucault, the author reaffirms citizenship and law in their various forms in relation to both bounded and unbounded serialities as the basis for democracy, beyond and despite governability. Latin America and especially Brazil provide the empirical focus for the discussion, albeit mediated by other countries, particularly India.
\end{abstract}

Key words: democracy; domination; India; Latin America; Brazil

\title{
RÉSUMÉ \\ Démocratie et Domination: Une Discussion (via Les Indes) Centrée sur l'Amérique Latine (Brésil)
}

L'universalisme et le particularisme deviennent des questions essentielles à la structuration de la pensée moderne, amenant à différentes conceptions de démocratie, citoyenneté et politique sociale. Dans ce texte on soutient, à l'inverse d'Habermas et ses disciples, qu'on ne peut jamais assimiler démocratie à domination. De même, contre Chatterjee et Foucault, on réaffirme la citoyenneté et le droit, sous leurs diverses formes, par rapport à des sérialités aussi bien ouvertes que fermées, comme étant la base de la démocratie, au-delà de la gouvernabilité et malgré celle-ci. L'Amérique Latine, et surtout le Brésil, sert de centre empirique de la discussion, sous la médiation d'autres pays, spécialement l'Inde.

Mots-clé: démocratie; domination; Inde; Amérique Latine; Brésil 